\title{
Quercetin is able to alleviate TGF- $\beta$-induced fibrosis in renal tubular epithelial cells by suppressing miR-21
}

\author{
YAOCHEN CAO*, JIALIN HU*, JIANYING SUI, LIMEI JIANG, YAKUN CONG and GUOQING REN \\ Department of Nephrology, Daqingshi No. 4 Hospital, Daqing, Heilongjiang 163712, P.R. China
}

Received February 2, 2018; Accepted June 1, 2018

DOI: $10.3892 /$ etm.2018.6489

\begin{abstract}
Patients with chronic kidney disease (CKD) are characterized by a gradual loss of kidney function over time. A number of studies have indicated that tubule interstitial fibrosis (TIF) is associated with the occurrence and development of CKD. The aim of the present study was to investigate the effect of quercetin treatment on the fibrosis of renal tubular epithelial cells and to determine whether the anti-fibrotic effects of quercetin are achieved via microRNA (miR)-21. Human tubular epithelial HK-2 cells were cultured with transforming growth factor (TGF)- $\beta$ to induce fibrosis and the expression of fibrotic markers collagen I, fibronectin, $\alpha$-smooth muscle actin (SMA) and epithelial-cadherin were measured using reverse transcription-quantitative polymerase chain reaction (RT-qPCR) and western blotting. Cells were treated with $7.5,15$ or $30 \mathrm{mg} / \mathrm{ml}$ quercetin, following which fibrosis and miR-21 expression were evaluated. Quercetin-treated cells were transfected with miR-21 mimics and the expression of fibrotic markers was examined using RT-qPCR. Finally, the expression of fibrosis-associated miR-21 target genes, phosphatase and tensin homolog (PTEN) and TIMP Metallopeptidase Inhibitor 3 (TIMP3), was measured in cells treated with quercetin with or without miR-21 mimics using RT-qPCR, western blotting and immunocytochemistry. The results revealed that TGF- $\beta$ treatment induced a significant increase in the expression of fibrotic markers in HK-2 cells, while quercetin treatment partially inhibited the fibrosis of HK-2 cells. Furthermore, quercetin treatment significantly inhibited TGF- $\beta$-induced miR-21 upregulation and transfection with miR-21 mimics reversed the anti-fibrotic effects of quercetin. Quercetin
\end{abstract}

Correspondence to: Dr Guoqing Ren, Department of Nephrology, Daqingshi No. 4 Hospital, 198 Central Street, Daqing, Heilongjiang 163712, P.R. China

E-mail: renguoqing1974@sina.com

*Contributed equally

Key words: quercetin, microRNA-21, tubule interstitial fibrosis, transforming growth factor- $\beta$ treatment markedly upregulated PTEN and TIMP3 expression, whereas transfection with miR-21 mimics reversed this effect. The results of the present study suggest that quercetin is able to alleviate TGF- $\beta$-induced fibrosis in HK- 2 cells via suppressing the miR-21 and upregulating PTEN and TIMP3. Quercetin may have potential as an anti-fibrotic treatment for patients with renal fibrosis.

\section{Introduction}

Chronic kidney disease (CKD) is the final stage of a number of renal diseases. In recent years, it has been reported that tubule interstitial fibrosis (TIF) is associated with the occurrence and development of CKD (1). Tubular epithelial cells (TECs) serve important roles in maintaining renal function and the progression of TIF (2). Kidney injury may lead to the phenotypic transformation of TECs (3), which is similar to the process of epithelial mesenchymal transition (EMT). Under such conditions, TECs acquire some properties of fibroblasts, producing excessive extracellular matrix (ECM) and related proteins, including collagen and fibronectin, leading to fibrosis of the kidney cells and eventual nephropathy $(4,5)$.

The pathogenesis of TIF remains unclear. It has been reported that transforming growth factor (TGF)- $\beta$ serves a central role in the onset and progression of kidney fibrosis (6-8). MicroRNAs (miRNAs or miRs) are a family of small non-coding RNAs 18-25 nucleotides in length (9). miRNAs are able to bind to the 3'-untranslated regions (3'-UTR) of their paired mRNAs to suppress the expression of target genes (10). A number of miRNAs have been reported to participate in the pathogenesis of many diseases, including cancers, autoimmune diseases, cardiovascular diseases and acute and chronic renal disease (10-12). However, the underlying mechanisms of miRNAs in renal diseases require further investigation.

Quercetin is a widely available flavonoid that can be isolated from many plants, vegetables and fruits (13). Increasing evidence has indicated that quercetin exerts various biological activities, such as antioxidant, anti-tumor, anti-angiogenesis and anti-inflammatory functions $(14,15)$. Quercetin has also been reported to have a therapeutic effect on renal function and tissue damage $(16,17)$. To the best of our knowledge, the effect of quercetin on kidney fibrosis and whether miRNAs are serving a role in quercetin-induced renal protective effects has not been reported. 
A previous study reported that the TGF- $\beta 1$ signaling pathway is vital for the induction of renal fibrosis (18). In the present study, in order to simulate renal fibrosis in vitro, the human tubular epithelial cell line HK-2 was treated with TGF- $\beta$ according to previous reports $(19,20)$. The role of miR-21 in mediating the renal protective effect of quercetin was assessed using TGF- $\beta$-induced fibrosis in HK- 2 cells to provide a theoretical basis for the treatment of nephropathy using quercetin.

\section{Materials and methods}

Cell culture and treatments. The human tubular epithelial cell line HK-2 was purchased from the American Type Culture Collection (ATCC, Manassas, VA, USA) and cultured according to the manufacturer's protocols. Cells were cultured in Dulbecco's Modification of Eagle's Medium (DMEM; Gibco; Thermo Fisher Scientific, Inc., Waltham, MA, USA) supplemented with $10 \%$ fetal bovine serum (FBS; Gibco; Thermo Fisher Scientific, Inc.), $100 \mathrm{U} / \mathrm{ml}$ penicillin and streptomycin in a humidified incubator at $37^{\circ} \mathrm{C}$ with $5 \% \mathrm{CO}_{2}$. Fibrosis was induced by treatment with $100 \mathrm{ng} / \mathrm{ml}$ TGF- $\beta$ for $72 \mathrm{~h}$. The quercetin groups were treated with medium containing 7.5, 15 or $30 \mathrm{mg} / \mathrm{ml}$ quercetin (Sigma-Aldrich; Merck KGaA, Darmstadt, Germany).

Cell proliferation detection. Cell Counting Kit-8 (CCK-8; Dojindo, Kumamoto, Japan) was used according to the manufacturer's protocol to assess cell proliferation. Briefly, HK-2 cells were treated with $7.5,15$ or $30 \mathrm{mg} / \mathrm{ml}$ quercetin for 24,48 and $72 \mathrm{~h}$. Cells were subsequently incubated with $10 \mu \mathrm{l} /$ well CCK 8 at $37^{\circ} \mathrm{C}$ for $4 \mathrm{~h}$. Finally, the optical density (OD) at $450 \mathrm{~nm}$ was measured using a multi-well spectrophotometer (Thermo Fisher Scientific, Inc.).

Cell transfection. miR-21 inhibitor and miR-21 mimic oligonucleotides (3'-AGUUGUAGUCAGACUAUUCGAU-5') were synthesized by Shanghai GenePharma Co., Ltd. (Shanghai, China). Cells were transfected with miR-21 inhibitor $(100 \mathrm{nM})$ or miR-21 mimics (50 nM) using Lipofectamine ${ }^{\circledR}$ RNAi Max (Thermo Fisher Scientific, Inc.). At $48 \mathrm{~h}$ post transfection, cells were trypsinized and harvested $\left(800 \mathrm{x} \mathrm{g}, 5 \mathrm{~min}, 4^{\circ} \mathrm{C}\right)$ for future analysis.

Reverse transcription-quantitative polymerase chain reaction (RT-qPCR). Total RNA was isolated from cells using TRIzol (Invitrogen; Thermo Fisher Scientific, Inc.). RT-qPCR was performed with an SYBR ExScript RT-PCR kit (Takara Bio, Inc., Dalian, China) on an ABI 7500 Real-Time PCR System machine (Applied Biosystems; Thermo Fisher Scientific, Inc.). Reverse transcription reaction was performed for $1 \mathrm{~h}$ at $37^{\circ} \mathrm{C}$ followed by $5 \mathrm{~min}$ at $95^{\circ} \mathrm{C}$. The thermocycling conditions for the qPCR step were as follows: $95^{\circ} \mathrm{C}$ for $30 \mathrm{sec}$ followed by 40 cycles of $95^{\circ} \mathrm{C}$ for $5 \mathrm{sec}$ and $60^{\circ} \mathrm{C}$ for $30 \mathrm{sec}$. The primers were synthesized by Sangon Biotech Co., Ltd. (Shanghai, China) with sequences as follows: Collagen I forward, 5'-TGGCCAAGA AGACATCCCTGAAGT-3' and reverse, 5'-ACATCAGGTTTC CACGTCTCACCA-3'; fibronectin forward, 5'-CCATCGCAA ACCGCTGCCAT-3' and reverse, 5'-AACACTTCTCAGCTA TGGGCTT-3'; GAPDH forward, 5'-AAGAAGGTGGTGAAG
CAGGC-3' and reverse, 5'-TCCACCACCCTGTTGCTGTA-3'; $\alpha$-smooth muscle actin ( $\alpha$-SMA) forward, 5'-ACTGAGCGT GGCTATTCCTCCGTT-3' and reverse, 5'-GCAGTGGCC ATCTCATTTTCA-3'; epithelial E-cadherin forward, 5'-TAC ACTGCCCAGGAGCCAGA-3' and reverse; 5'-TGGCACCAG TGTCCGGATTA-3'; phosphatase and tensin homolog (PTEN) forward, 5'-CAAGATGATGTTTGAAACTATTCCAATG-3' and reverse, 5'-CCTTTAGCTGGCAGACCACAA-3'; TIMP metallopeptidase inhibitor 3 (TIMP3) forward, 5'-CTGCAA GGGCTGGGCATC-3' and reverse, 5'-TCCATGGCCCGG TTGGCAGTGTGGAG-3'; U6 forward, 5'-ATAAGGATC CGGTCTCGCTATGAGGGCCTATTTCCCATG-3' and reverse, 5'-ATAATGTACAGGTCTCCCATGTAACTTGCT ATTTCTAGCTC-3'. The relative expression of collagen I, fibronectin, SMA, (E)-cadherin, PTEN and TIMP3 in each sample was normalized to the expression of GAPDH using the $2^{-\Delta \Delta \mathrm{Cq}}$ method (21). miR-21 expression was examined using a Hairpin-it ${ }^{\mathrm{TM}}$ miRNAs qPCR Quantitation kit (Shanghai GenePharma Co., Ltd.) and U6 was used for normalization. Primers, forward 5'-GCCGCTAGCTTATCAGACTGATGT-3' and reverse 5'-GTGCAGGGTCCGAGGT-3', were supplied by Sangon Biotech Co., Ltd.

Western blotting. Cells were lysed using radioimmunoprecipitation assay buffer (Beyotime Institute of Biotechnology, Haimen, China). Bradford assays were used to determine the concentration of total extracted protein. Total proteins $(40 \mu \mathrm{g})$ were loaded and separated on $10 \%$ SDS-PAGE gels. Proteins were transferred onto polyvinylidene fluoride membranes, blocked in 5\% non-fat milk for $2 \mathrm{~h}$ at room temperature and incubated with the following primary antibodies: Anti-collagen I (1:1,000; cat. no. 84336; Cell Signaling Technology, Inc., Danvers, MA, USA), anti-fibronectin (1:200; cat. no. ab2413; Abcam, Cambridge, MA, USA), anti- $\alpha$-SMA (1:1,000; cat. no. 19245; Cell Signaling Technology, Inc.), anti-E-cadherin (1:1,000; cat. no. 3195; Cell Signaling Technology, Inc.), anti-PTEN (1:1,000; cat. no. 9188; Cell Signaling Technology, Inc.), anti-TIMP3 (1:1,000; cat. no. 5673; Cell Signaling Technology, Inc.) and anti- $\beta$-actin (1:1,000; cat. no.4970; Cell Signaling Technology, Inc.) overnight at $4^{\circ} \mathrm{C}$. The membranes were subsequently washed three times with TBST buffer and incubated with the secondary horseradish peroxidase-linked antibody goat anti-rabbit IgG (1:1,000; cat. no. A0208; Beyotime Institute of Biotechnology) for $1 \mathrm{~h}$ at room temperature, following which they were washed three times with TBST buffer, incubated with BeyoECL Plus (Beyotime Institute of Biotechnology) and visualized using ChemiDoc ${ }^{\mathrm{TM}} \mathrm{XRS}+$ System (Bio-Rad Laboratories, Inc., Hercules, CA, USA). $\beta$-actin was used as the internal control.

Immunocytochemistry (IHC). For IHC, cells were fixed in $4 \%$ paraformaldehyde overnight at room temperature and permeabilized with $0.1 \%$ Triton $\mathrm{X}-100$ in $0.5 \%$ bovine serum albumin (Sigma-Aldrich; Merck KGaA) for $30 \mathrm{~min}$ at room temperature. Cells were incubated with the rabbit anti-human PTEN (1:125; cat. no. 9188; Cell Signaling Technology, Inc.) primary antibody overnight at $4^{\circ} \mathrm{C}$. Following washing for three times with $\mathrm{PBS}$, cells were incubated with Alexa Fluor ${ }^{\circledR}$ 488-conjugated rabbit mAb (1:800; cat. no. 9854; Cell 
Signaling Technology, Inc.) secondary antibody for $30 \mathrm{~min}$ at $37^{\circ} \mathrm{C}$. Cells were visualized using a fluorescent microscope (magnification, $\mathrm{x} 400$ ).

Statistical analysis. Statistical analysis was performed using SPSS 19.0 (IBM Corp., Armonk, NY, USA). Data are presented as the mean \pm standard deviation and a two-independent sample t-test was performed used to make comparisons between two groups. One-way analysis of variance followed by Dunnett's test was used for multiple group comparisons. $\mathrm{P}<0.05$ was considered to indicate a significant difference.

\section{Results}

TGF- $\beta$ treatment induces fibrosis in $\mathrm{HK}-2$ cells. HK-2 cells were treated with TGF- $\beta$ and the expression of fibrotic markers was evaluated using RT-qPCR and western blotting. Compared with untreated cells, TGF- $\beta$ induced a significant increase in the expression of fibrotic markers collagen I, fibronectin, $\alpha$-SMA and E-cadherin at the mRNA (Fig. 1A) and protein levels (Fig. 1B and C), suggesting that TGF- $\beta$ treatment induces a fibrosis-like state in HK-2 cells in vitro.

Quercetin alleviates TGF- $\beta$-induced fibrosis in HK- 2 cells. To assess whether quercetin is able to alleviate TGF- $\beta$-induced fibrosis in HK- 2 cells, TGF- $\beta$-stimulated HK- 2 cells were treated with different concentrations of quercetin and the expression of fibrotic markers was evaluated using RT-qPCR and western blotting. CCK- 8 results revealed that treatment with 7.5 and $15 \mathrm{mg} / \mathrm{ml}$ quercetin had a limited effect on cell growth, while $30 \mathrm{mg} / \mathrm{ml}$ quercetin had a slight cytotoxic effect (Fig. 2A). Compared with the TGF- $\beta$ group, TGF $-\beta+7.5 \mathrm{mg} / \mathrm{ml}$ quercetin induced a significant decrease in the expression of collagen I, fibronectin and $\alpha$-SMA. In the TGF- $\beta+15 \mathrm{mg} / \mathrm{ml}$ and TGF- $\beta+30 \mathrm{mg} / \mathrm{ml}$ quercetin groups, a significant decrease in collagen I, fibronectin, $\alpha$-SMA and E-cadherin mRNA expression was observed (Fig. 2B). Furthermore, quercetin induced a significant decrease in the protein expression of fibrotic markers (Fig. 2C). The effect of quercetin on $\alpha$-SMA and fibronectin expression was dose-dependent (Fig. 2C). Based on these results, $15 \mathrm{mg} / \mathrm{ml}$ quercetin had been selected for further investigations.

Quercetin alleviates TGF- $\beta$ induced fibrosis via regulating $m i R-21$ expression. The role of miR-21 in quercetin-induced anti-fibrosis was investigated. TGF- $\beta$ treatment induced a significant increase in miR-21 expression, while quercetin treatment decreased the TGF- $\beta$-induced miR- 21 upregulation in HK-2 cells (Fig. 3A). Transfection with miR-21 mimics inhibited the quercetin-induced anti-fibrotic effects, increasing the expression of collagen I, fibronectin, $\alpha$-SMA and E-cadherin at the mRNA (Fig. 3B) and protein levels (Fig. 3C and D).

Quercetin increases the expression of miR-21 target genes in TGF- $\beta$ treated HK- 2 cells. PTEN and TIMP 3 have previously been confirmed as direct targets of miR-21 $(22,23)$. To further explore the mechanism of miR-21 in quercetin-induced anti-fibrotic effects, the expression of PTEN and TIMP3 in
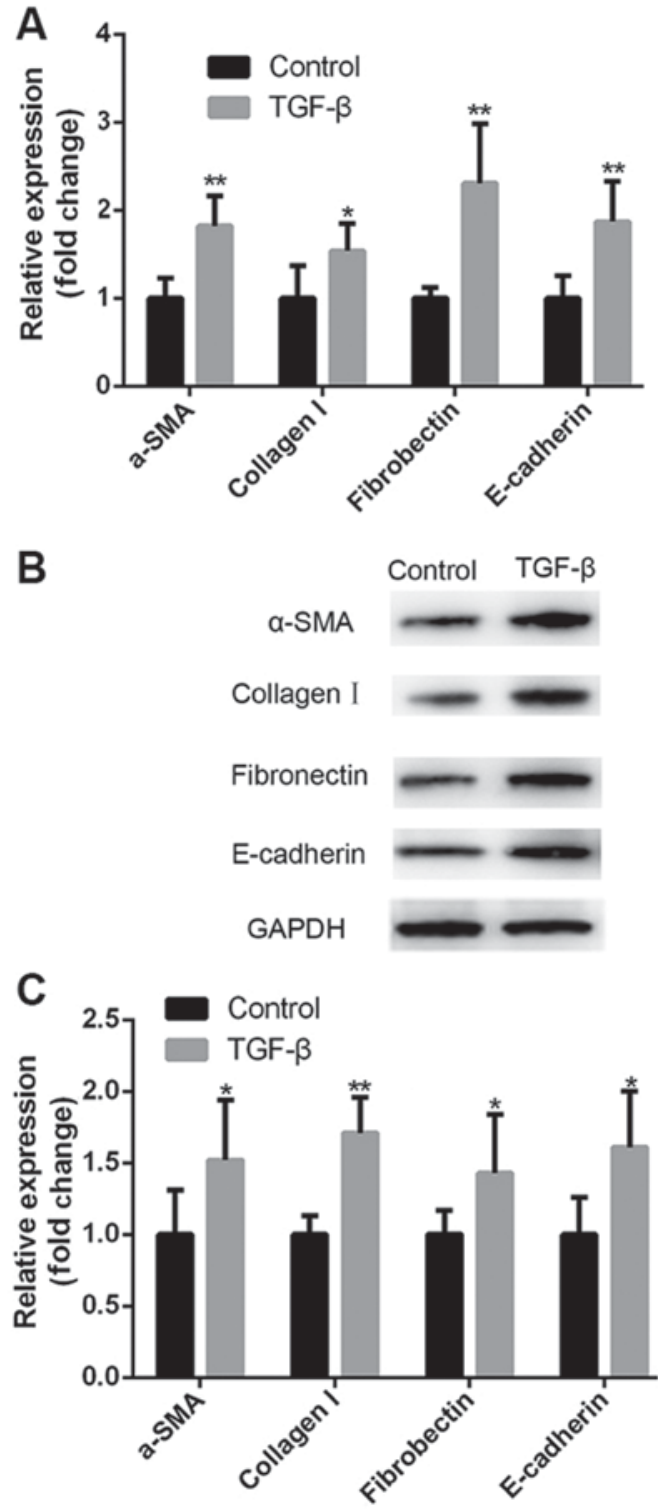

Figure 1. TGF- $\beta$ treatment induces a fibrosis-like state in HK-2 cells in vitro. Relative expression of fibrotic markers $\alpha$-SMA, collagen I, fibronectin and E-cadherin at the (A) mRNA and (B) protein levels. (C) Quantified results of western blotting. ${ }^{*} \mathrm{P}<0.05$ and ${ }^{* *} \mathrm{P}<0.01$ vs. Control. TGF- $\beta$, transforming growth factor- $\beta$; $\alpha$-SMA, $\alpha$-smooth muscle actin; E-cadherin, epithelial cadherin.

untreated fibrotic and quercetin-treated fibrotic HK-2 cells was assessed. Quercetin treatment induced a significant increase in the expression of PTEN and TIMP 3 at the mRNA (Fig. 4A) and protein levels (Fig. 4B-D). Furthermore, transfection with miR-21 mimics partially inhibited the quercetin-induced increase in PTEN and TIMP3 expression (Fig. 4A-C).

\section{Discussion}

The renal protective effect of quercetin has been discussed in a number of studies. Gelen et al (24) reported that quercetin protected renal function in a rat model of obesity, while Yuksel et al (25) demonstrated that quercetin was able to reduce methotrexate-induced oxidative stress in rat models, suggesting that quercetin can alleviate methotrexate-induced 

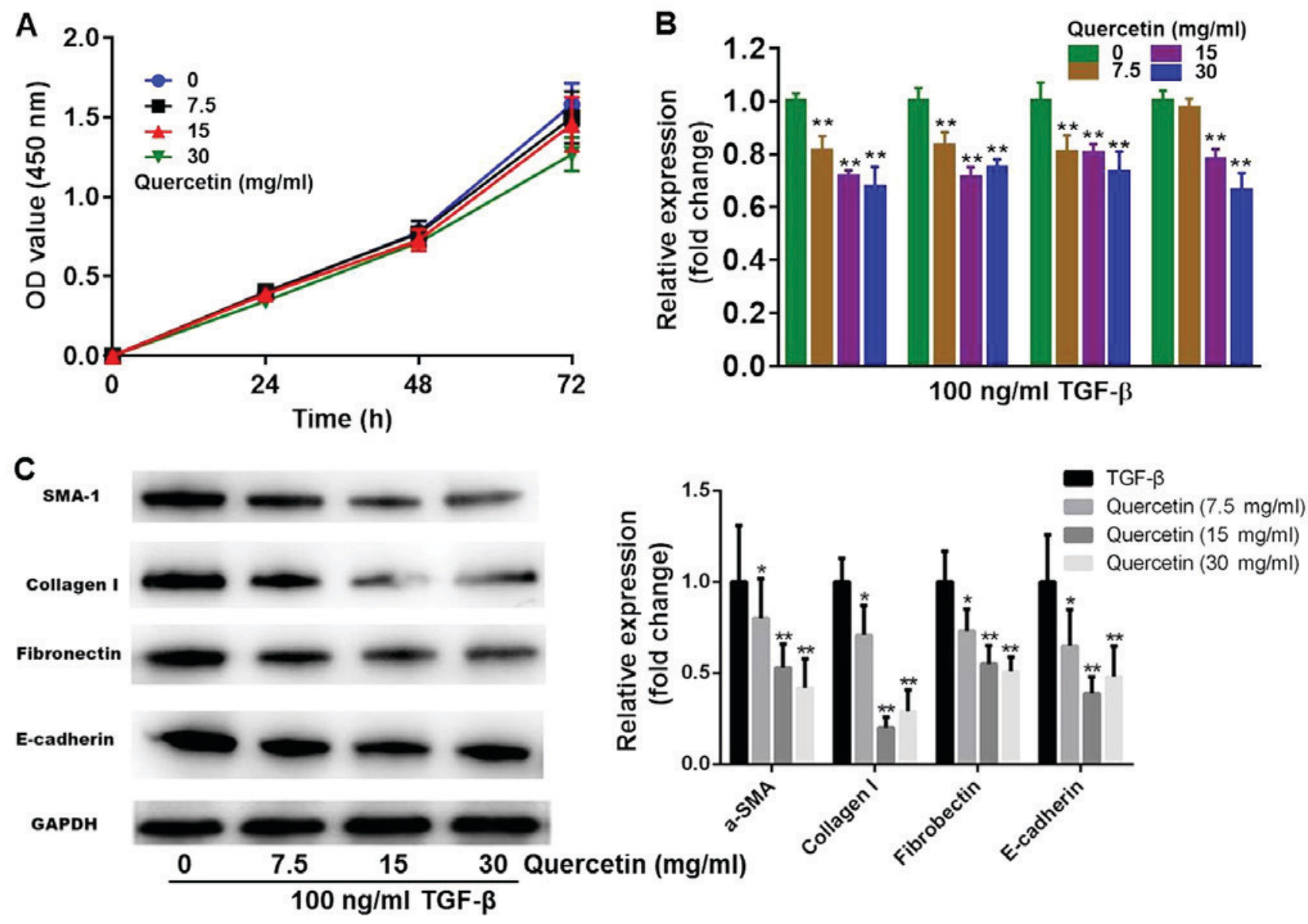

Figure 2. Quercetin alleviates TGF- $\beta$-induced fibrosis in HK-2 cells. (A) HK-2 cells were treated with 7.5, 15 or $30 \mathrm{mg} / \mathrm{ml}$ quercetin for 24,48 or $72 \mathrm{~h}$ and the OD was measured at $450 \mathrm{~nm}$. Relative expression of fibrotic markers $\alpha$-SMA, collagen I, fibronectin and E-cadherin at the (B) mRNA and (C) protein levels. ${ }^{*} \mathrm{P}<0.05$ and ${ }^{* * *} \mathrm{P}<0.01$ vs. Control. TGF- $\beta$, transforming growth factor- $\beta$; OD, optical density; $\alpha$-SMA, $\alpha$-smooth muscle actin; E-cadherin, epithelial cadherin.

renal damage and restore renal function. Elbe et al (26) revealed that quercetin is able to reduce ciprofloxacin-induced oxidative stress in rats, suggesting that quercetin may be an effective treatment for injuries. In the present study, fibrosis was induced in HK- 2 cells using TGF- $\beta$ and it was demonstrated that treatment with $7.5,15$ or $30 \mathrm{mg} / \mathrm{ml}$ quercetin induced a significant decrease in the expression of fibrotic markers. These results suggest that the anti-fibrotic effect of quercetin may not be dose-dependent, as no significant difference was observed in the expression of fibrotic markers between the 15 and $30 \mathrm{mg} / \mathrm{ml}$ groups. Taken together, these results indicate that treatment with an appropriate dosage of quercetin may effectively alleviate TGF- $\beta$-induced fibrosis in HK-2 cells in vitro.

miR-21 has previously been reported to be a profibrotic microRNA. miR-21-5p expression is associated with the incidence of renal fibrosis in patients with IgA nephropathy (27), while an in vitro study revealed that miR-21 may serve a role in the pathogenesis of TIF by targeting DDAH1 (28). Furthermore, Wang et al (29) demonstrated that miR-21 overexpression can cause renal fibrosis via the MMP9/TIMP1 signaling pathway in mice, suggesting that miR-21 has potential as a novel therapeutic target for the management of diabetic nephropathy. In the present study, it was demonstrated that miR-21 was upregulated in fibrosis in HK-2 cells, which is consistent with previous findings. It was also observed that quercetin treatment induced a significant decrease in the expression of miR-21, suggesting that miR-21 may serve a role in the mechanism by which quercetin induces anti-fibrotic effects. Furthermore, transfection with miR-21 mimics partially inhibited quercetin-induced anti-fibrotic effects. These results suggest that the anti-fibrotic effects of quercetin may be achieved in part by downregulating miR-21, a profibrotic factor.

PTEN and TIMP3 are known to be anti-fibrotic factors (30-32) and are downregulated in fibrotic renal tissues. Downregulation of either PTEN (29) or TIMP3 (31) may enhance the degree of TIF. Bioinformatics has been used to predict PTEN and TIMP3 as direct targets of miR-21, which has been confirmed using dual-luciferase reporter assays $(32,33)$. To further explore the mechanism of miR-21 in quercetin-induced anti-fibrotic effects, the expression of PTEN and TIMP3 was compared between quercetin-treated and untreated fibrotic HK-2 cells. The results indicated that quercetin treatment induced a significant increase in the expression of PTEN and TIMP3 at the mRNA and protein levels, while transfection with miR-21 mimics partially inhibited the quercetin-induced PTEN and TIMP3 upregulation. These results suggest that quercetin downregulates miR-21 and upregulates anti-fibrotic gene expression, thereby 

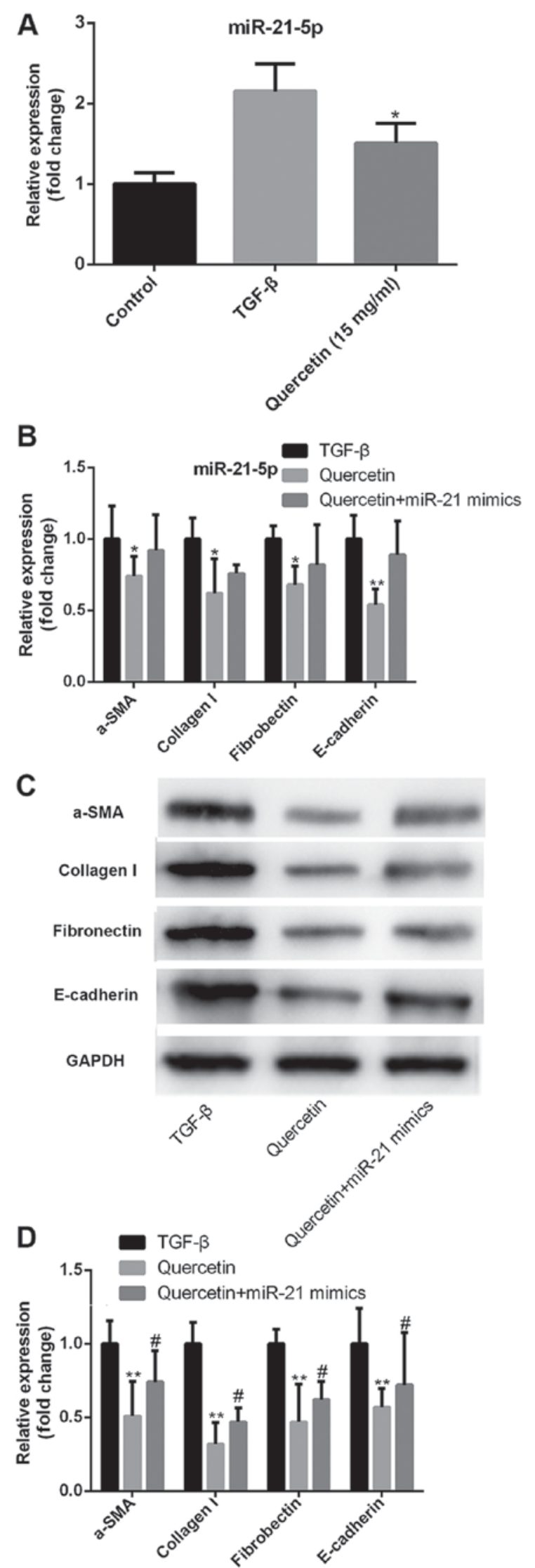

Figure 3. Quercetin alleviates TGF- $\beta$-induced fibrosis by regulating the expression of miR-21. (A) Relative expression of miR-17-5p mRNA. Relative expression of fibrotic markers $\alpha$-SMA, collagen I, fibronectin and E-cadherin at the (B) mRNA and (C) protein levels. (D) Quantified results of western blotting. ${ }^{*} \mathrm{P}<0.05$ and ${ }^{* * *} \mathrm{P}<0.01$ vs. TGF- $\beta ;{ }^{*} \mathrm{P}<0.05$ vs. quercetin. TGF- $\beta$, transforming growth factor- $\beta ;$ miR, microRNA; $\alpha$-SMA, $\alpha$-smooth muscle actin; E-cadherin, epithelial cadherin.
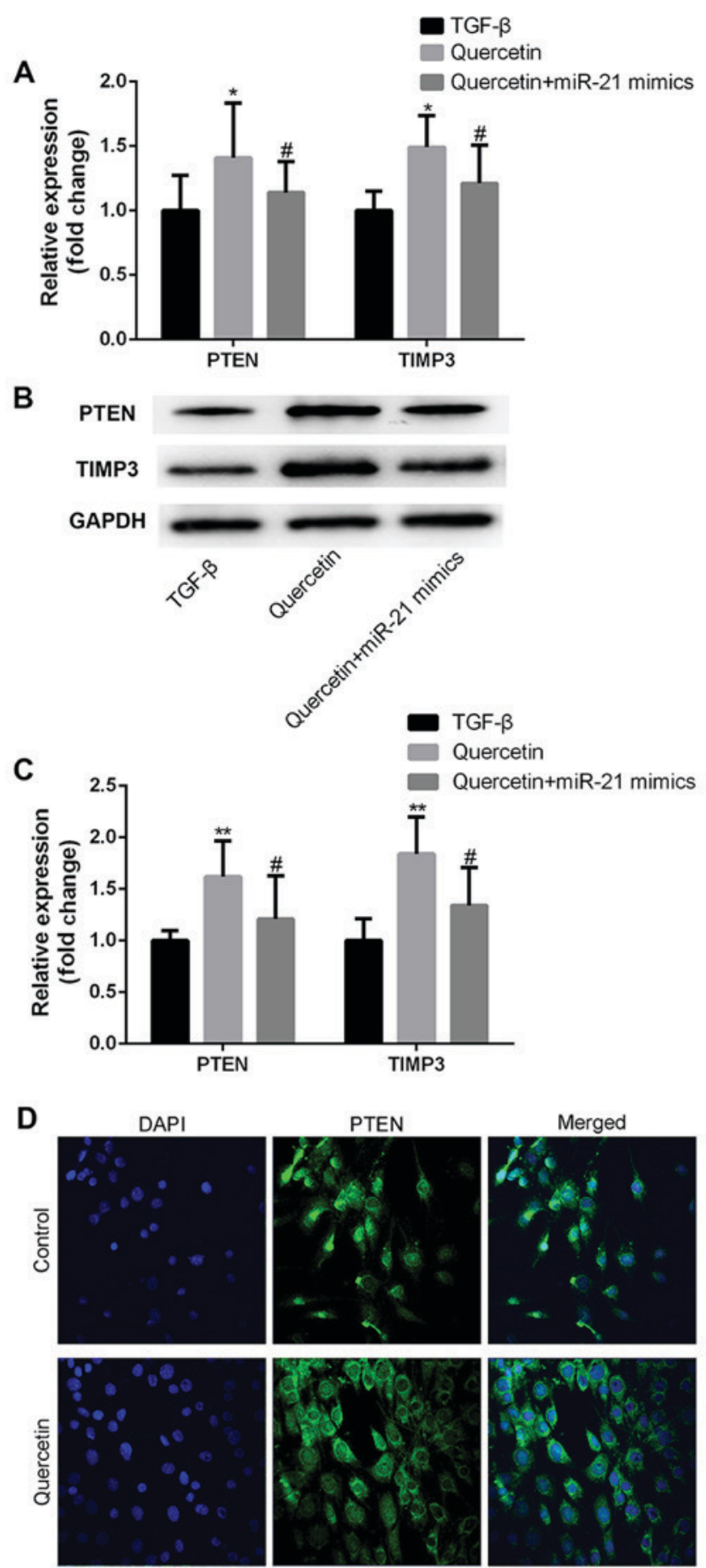

Figure 4. Quercetin increases the expression of miR-21 target genes in TGF- $\beta$-treated HK-2 cells. Relative expression of PTEN and TIMP3 at the (A) mRNA and (B) protein levels. (C) Quantified results of western blotting. (D) Immunohistochemistry results for PTEN expression. ${ }^{*} \mathrm{P}<0.05$ and ${ }^{* *} \mathrm{P}<0.01$ vs. TGF- $\beta$; ${ }^{*} \mathrm{P}<0.05$ vs. quercetin. miR, microRNA; TGF- $\beta$, transforming growth factor- $\beta$; PTEN, phosphatase and tensin homolog; TIMP3, TIMP Metallopeptidase Inhibitor 3.

inhibiting the progression of kidney fibrosis and protecting renal function.

The present study is not without limitations. Only cellular experiments were performed; in future studies, the roles of quercetin and miR-21 should be further explored using animal models. In conclusion, the results of the present study suggest that quercetin is able to alleviate TGF- $\beta$-induced 
fibrosis in tubular epithelial cells by suppressing miR-21. These findings provide a novel insight into the effects of quercetin as an anti-fibrotic drug for the treatment of renal fibrosis.

\section{Acknowledgements}

Not applicable.

\section{Funding}

No funding received.

\section{Availability of data and materials}

The datasets used and/or analyzed during the current study are available from the corresponding author on reasonable request.

\section{Authors' contributions}

YCao and $\mathrm{JH}$ contributed to conception and design of the study. YCao, JH and JS performed the experiments. LJ conducted data acquisition, analysis and interpretation. YCong was involved in data analysis, interpretation and manuscript development. GR guided the experimental design, reviewed the manuscript and supervised the study. All authors read and approved the final version of this manuscript and agreed to be accountable for all aspects of this study.

\section{Ethics approval and consent to participate}

Not applicable.

\section{Patient consent for publication}

Not applicable.

\section{Competing interests}

The authors declare that they have no competing interests.

\section{References}

1. Zhou D, Fu H, Zhang L, Zhang K, Min Y, Xiao L, Lin L, Bastacky SI and Liu Y: Tubule-derived wnts are required for fibroblast activation and kidney fibrosis. J Am Soc Nephrol 28 : 2322-2336, 2017

2. Omata M, Doke Y, Yamada C, Kawashima K, Sho R, Enomoto K, Furuya $\mathrm{M}$ and Inomata N: Hepatocyte nuclear factor-1 $\beta$ induces redifferentiation of dedifferentiated tubular epithelial cells. PLoS One 11: e0154912, 2016.

3. Lu H, Chen B, Hong W, Liang Y and Bai Y: transforming growth factor- $\beta 1$ stimulates hedgehog signaling to promote epithelial-mesenchymal transition after kidney injury. FEBS J 283: 3771-3790, 2016.

4. Chen SJ, Wu P, Sun LJ, Zhou B, Niu W, Liu S, Lin FJ and Jiang GR: miR-204 regulates epithelial-mesenchymal transition by targeting SP1 in the tubular epithelial cells after acute kidney injury induced by ischemia-reperfusion. Oncol Rep 37: 1148-1158, 2017.

5. Jara P, Calyeca J, Romero Y, Plácido L, Yu G, Kaminski N, Maldonado V, Cisneros J, Selman M and Pardo A: Matrix metalloproteinase (MMP)-19-deficient fibroblasts display a profibrotic phenotype. Am J Physiol Lung Cell Mol Physiol 308: L511-L522, 2015.
6. Meng XM, Zhang Y, Huang XR, Ren GL, Li J and Lan HY: Treatment of renal fibrosis by rebalancing TGF- $\beta / \mathrm{Smad}$ signaling with the combination of asiatic acid and naringenin. Oncotarget 6: 36984-36997, 2015.

7. Muñoz-Félix JM, González-Núñez M, Martínez-Salgado $C$ and López-Novoa JM: TGF-U/BMP proteins as therapeutic targets in renal fibrosis. Where have we arrived after 25 years of trials and tribulations? Pharmacol Ther 156: 44-58, 2015

8. Vega G, Alarcón S and San Martin R: The cellular and signalling alterations conducted by TGF- $\beta$ contributing to renal fibrosis. Cytokine 88: 115-125, 2016.

9. Garzon R, Calin GA and Groce CM: MicroRNAs in cancer. Annu Rev Med 60: 167-179, 2009.

10. Han F, Konkalmatt P, Chen J, Gildea J, Felder RA, Jose PA and Armando I: miR-217 mediates the protective effects of the dopamine D2 receptor on fibrosis in human renal proximal tubule cells. Hypertension 65: 1118-1125, 2015.

11. He F, Peng F, Xia X, Zhao C, Luo Q, Guan W, Li Z, Yu X and Huang F: miR-135a promotes renal fibrosis in diabetic nephropathy by regulating TRPC1. Diabetologia 57: 1726-1736, 2014.

12. Liu D, Zhang N, Zhang J, Zhao H and Wang X: miR-410 suppresses the expression of interleukin- 6 as well as renal fibrosis in the pathogenesis of lupus nephritis. Clin Exp Pharmacol Physiol 43: 616-625, 2016

13. Han M, Song Y and Zhang X: Quercetin suppresses the migration and invasion in human colon cancer caco-2 cells through regulating toll-like receptor 4/nuclear factor-kappa B pathway. Pharmacogn Mag 12 (Suppl 2): S237-S244, 2016.

14. Chan CY, Lien CH, Lee MF and Huang CY: Quercetin suppresses cellular migration and invasion in human head and neck squamous cell carcinoma (HNSCC). Biomedicine (Taipei) 6: 15, 2016.

15. Song NR, Chung MY, Kang NJ, Seo SG, Jang TS, Lee HJ and Lee KW: Quercetin suppresses invasion and migration of H-Ras-transformed MCF10A human epithelial cells by inhibiting phosphatidylinositol 3-kinase. Food Chem 142: 66-71, 2014.

16. Chen BL, Wang LT, Huang KH, Wang CC, Chiang CK and Liu SH: Quercetin attenuates renal ischemia/reperfusion injury via an activation of AMP-activated protein kinase-regulated autophagy pathway. J Nutr Biochem 25: 1226-1234, 2014.

17. Erboga M, Aktas C, Erboga ZF, Donmez YB and Gurel A: Quercetin ameliorates methotrexate-induced renal damage, apoptosis and oxidative stress in rats. Ren Fail 37: 1492-1497, 2015.

18. Kou B, Liu W, Tang X and Kou Q: HMGA2 facilitates epithelial-mesenchymal transition in renal cell carcinoma by regulating the TGF- $\beta /$ Smad2 signaling pathway. Oncol Rep 39: 101-108, 2018.

19. Kinashi H, Falke LL, Nguyen TQ, Bovenschen N, Aten J, Leask A, Ito Y and Goldschmeding R: Connective tissue growth factor regulates fibrosis-associated renal lymphangiogenesis. Kidney Int 92: 850-863, 2017.

20. Ma J, Zhang L, Hao J, Li N, Tang J and Hao L: Up-regulation of microRNA-93 inhibits TGF- $\beta 1$-induced EMT and renal fibrogenesis by down-regulation of Orail. J Pharmacol Sci 136: 218-227, 2018.

21. Livak KJ and Schmittgen TD: Analysis of relative gene expression data using real-time quantitative PCR and the 2(-Delta Delta C(T)) method. Methods 25: 402-408, 2001.

22. Shi B, Wang Y, Zhao R, Long X, Deng W and Wang Z: Bone marrow mesenchymal stem cell-derived exosomal miR-21 protects C-kit+ cardiac stem cells from oxidative injury through the PTEN/PI3K/Akt axis. PLoS One 13: e0191616, 2018.

23. Gutsaeva DR, Thounaojam M, Rajpurohit S, Powell FL, Martin PM, Goei S, Duncan M and Bartoli M: STAT3-mediated activation of miR-21 is involved in down-regulation of TIMP3 and neovascularization in the ischemic retina. Oncotarget 8: 103568-103580, 2017.

24. Gelen V, Şengül E, Gedikli S, Gür C and Özkanlar S: Therapeutic effect of quercetin on renal function and tissue damage in the obesity induced rats. Biomed Pharmacother 89: 524-528, 2017.

25. Yuksel Y, Yuksel R, Yagmurca M, Haltas H, Erdamar H, Toktas M and Ozcan O: Effects of quercetin on methotrexate-induced nephrotoxicity in rats. Hum Exp Toxicol: Mar 22, 2016 (Epub ahead of print).

26. Elbe H, Dogan Z, Taslidere E, Cetin A and Turkoz Y: Beneficial effects of quercetin on renal injury and oxidative stress caused by ciprofloxacin in rats: A histological and biochemical study. Hum Exp Toxicol 35: 276-281, 2016. 
27. Hennino MF, Buob D, Van der Hauwaert C, Gnemmi V, Jomaa Z, Pottier N, Savary G, Drumez E, Noël C, Cauffiez C and Glowacki F: miR-21-5p renal expression is associated with fibrosis and renal survival in patients with IgA nephropathy. Sci Rep 6: 27209, 2016.

28. Liu XJ, Hong Q, Wang Z, Yu YY,Zou X and Xu LH: MicroRNA21 promotes interstitial fibrosis via targeting DDAH1: A potential role in renal fibrosis. Mol Cell Biochem 411: 181-189, 2016.

29. Wang J, Gao Y, Ma M, Li M, Zou D, Yang J, Zhu Z and Zhao X: Effect of miR-21 on renal fibrosis by regulating MMP-9 and TIMP1 in kk-ay diabetic nephropathy mice. Cell Biochem Biophys 67: 537-546, 2013.

30. Lan R, Geng H, Polichnowski AJ, Singha PK, Saikumar P, McEwen DG, Griffin KA, Koesters R, Weinberg JM, Bidani AK, et al: PTEN loss defines a TGF- $\beta$-induced tubule phenotype of failed differentiation and JNK signaling during renal fibrosis. Am J Physiol Renal Physiol 302: F1210-F1223, 2012.

31. Kassiri Z, Oudit GY, Kandalam V, Awad A, Wang X, Ziou X, Maeda N, Herzenberg AM and Scholey JW: Loss of TIMP3 enhances interstitial nephritis and fibrosis. J Am Soc Nephrol 20: 1223-1235, 2009.
32. McClelland AD, Herman-Edelstein M, Komers R, Jha JC, Winbanks CE, Hagiwara S, Gregorevic P, Kantharidis P and Cooper ME: miR-21 promotes renal fibrosis in diabetic nephropathy by targeting PTEN and SMAD7. Clin Sci (Lond) 129: 1237-1249, 2015.

33. Wang N, Zhang CQ, He JH, Duan XF, Wang YY, Ji X, Zang WQ, Li M, Ma YY, Wang T and Zhao GQ: miR-21 down-regulation suppresses cell growth, invasion and induces cell apoptosis by targeting FASL, TIMP3, and RECK genes in esophageal carcinoma. Dig Dis Sci 58: 1863-1870, 2013.

cc) (i)(9) This work is licensed under a Creative Common Attribution-NonCommercial-NoDerivatives 4.0 International (CC BY-NC-ND 4.0) License. 